\section{DIARIO DE UN TALLER DE HUMOR GRÁFICO E HISTORIETA COSTUMBRISTA}

\author{
Mauro Entrialgo \\ Dibujante de historietas, entre otras cosas
}

\begin{abstract}
The author of this text gave lessons of graphic humour and comics dealing with local customs, in the classrooms at the Circulo de Bellas Artes in Madrid during a week in the 2010 summer. His report about these days shows a way to consider the teaching of the comic that places the information about the media and its own narrative tools in close-up and then, the mere plastic accuracy. This way of teaching also proposes specific exercises and alternation of new and traditional technologies. Giving the creative historical precedents and the sector publishing reality, is also a matter of importance from a professional point of view. At the same time, the author explains his theory on the humouristic speech, some considerations about the nature of the drawing and championed a very large definition of the two words: "cartoon story".
\end{abstract}

KEY WORDS: Cartoon story; humour; literary genre dealing with local customs; practical lessons; education; mechanisms; structure; drawing; story; teaching; exercises; story; technologies; training; profession; drawing.

Los autores de historietas no estamos obligados laboralmente a establecer contacto presencial diario con otros seres humanos. Esta característica de la profesión facilita grandes placeres solitarios como la posibilidad de trabajar en pijama, pero también aviva tendencias asociales. Con la intención de prevenir estas últimas, aunque la docencia y el hablar en público en general no son el tipo de actividades que más cómodo me hacen sentir, de vez en cuando me fuerzo a aceptar propuestas que me hagan abandonar mi cueva e interactuar con personas de carne y hueso. El verano pasado, por ejemplo, acepté impartir un taller de humor gráfico e historieta de 20 horas en el madrileño Círculo de Bellas Artes (del 28 de junio al 2 de julio de 2010). Lo que prosigue es un relato en forma de diario que reconstruye esos días de modo muy resumido.

\section{JOURNAL OF A STUDIO WORKING ON GRAPHIC HUMOR AND CARTOON STORIES RELATED TO LOCAL CUSTOMS}

RESUMEN: El autor de este texto impartió un taller de humor gráfico e historieta costumbrista en las aulas del madrileño Círculo de Bellas Artes durante una semana del verano de 2010. Su relato de aquellos días esboza una forma de abordar la enseñanza de la historieta que coloca en primer término el conocimiento del medio y sus herramientas narrativas sobre la mera habilidad plástica. En esa dirección, propone ejercicios concretos y procedimientos que alternan nuevas y tradicionales tecnologías. También destaca la importancia formativa de dar a conocer los antecedentes creativos históricos del medio y la realidad editorial del sector desde el punto de vista profesional, al mismo tiempo que expone fugazmente su particular teoría sobre la estructura del discurso humorístico, emite diversas consideraciones sobre la naturaleza del dibujo y aboga por una amplísima definición del término historieta.

PALABRAS CLAVE: Historieta; humor; costumbrismo; taller; educación; mecanismos; estructura; dibujo; narración; enseñanza; ejercicios; narración; tecnologías; formación; profesión; dibujo.

\section{DE JUNIO}

Hace unas semanas entregué este texto para describir las intenciones del curso a los posibles interesados:

Acercamiento a la profesión del dibujante de historietas tanto desde el punto de vista creativo como laboral.

Por un lado se pretende desarrollar la capacidad práctica de narrar historias con palabras y dibujos asimilando mediante ejercicios los fundamentos de este lenguaje, los mecanismos del humor y el proceso de expresar ideas gráficamente.

Por otro, se trata de divulgar aspectos menos creativos del medio pero cuyo conocimiento resulta igual de necesario en la práctica profesional: trayectoria de sus formatos comerciales, posibles sistemas de difusión de la obra, los pormenores de los contratos editoriales o los métodos habituales de retribución económica. 
Hoy doy por terminado un guión de contenidos que considero se ajusta a esas intenciones. Por otra parte, como aprecio interesante que los alumnos vean reproducidos algunos de sus trabajos públicamente abro un blog (http://eltallerdelcirculo.blogspot.com) en el que iré colgando los que estime oportuno a medida que los vayan produciendo.

\section{DE JUNIO}

Empieza el curso. La convocatoria ha tenido éxito y se han apuntado veintitantas personas, casi el máximo permitido de 30. Los técnicos de la institución me facilitan y ponen en marcha el ordenador conectado a Internet con proyector que solicité. Compruebo también el material que pedí: folios, lápices corrientes, gomas, sacapuntas, rotuladores negros y rojos, cajas de acuarelas baratas de un "Todo a cien" y cientos de pósits de colores. Para aprender a contar mediante palabras y dibujos, nos sobra.

Empezamos con un pequeño cuestionario escrito que deberán responder escuetamente y que me permitirá conocer el grado de experiencia y conocimiento de la clase y ajustar mis ejercicios y explicaciones.

1. ¿Qué experiencia tienes haciendo historietas? ¿Has publicado en revistas, fanzines 0 webcomics?

2. ¿Lo has hecho alguna vez de forma profesional? En caso negativo, ¿te gustaría dedicarte a dibujar cómics? ¿De qué tipo?

3. ¿Cuántas páginas de historietas completas calculas que habrás dibujado en tu vida?

4. ¿Lees habitualmente historietas? ¿Qué géneros y autores son tus favoritos?

5. ¿Qué es una viñeta? ¿y una tira?

6. ¿Qué es un comic-book? ¿y una novela gráfica?

Recojo sus respuestas y empezamos la clase. Dibujar es representar mediante líneas en un plano la idea de algo material o inmaterial. Si el dibujante consigue con su representación la finalidad que buscaba, su dibujo está "bien hecho". "Dibujar bien" no es otra cosa que conseguir ese objetivo. Un garabato de un hombre en la puerta de un retrete de caballeros que no da lugar a confusión está perfectamente bien dibujado si su autor buscaba simplemente eso: indicar cuál era el retrete de caballeros. Si en las instrucciones de montaje de un mueble no reconocemos una pieza allí representada, por muy bonito, realista o trabajado que sea su dibujo, es evidente que está muy mal hecho. De igual manera, cuando elaboramos una historieta con el objetivo primordial de contar una historia, todo dibujo que entorpezca la narración por ofrecer dificultades de interpretación estará mal dibujado. Nosotros vamos a dibujar ahora con el único fin de que nuestras representaciones gráficas de objetos materiales o ideas inmateriales sean interpretadas de manera correcta. Si lo conseguimos, demostraremos que sabemos dibujar lo suficientemente bien como para hacer historietas. Para este cometido, la habilidad técnica no es lo más importante: lo más importante es fijarse. Dibujar es, en primer lugar, fijarse. Y todos sabemos fijarnos o podemos aprender a hacerlo con suma facilidad.

Comenzamos con un ejercicio: pido que dibujen sobre un pósit una pajarita de papel. Los resultados, que pego componiendo un gran rectángulo en una de las paredes de la estancia, son desastrosos con la excepción de los de un par de espabilados que han construido, sin pedirme permiso, una pajarita de papel de verdad para utilizarla como modelo (imagen 1). Cojo la figura, la hago circular entre la clase y les pido a todos que se fijen en ella. También busco una fotografía de otra pajarita en Internet y la proyecto durante un par de minutos. Después apago el proyector y arrojo la figura a la papelera. Les pido de nuevo que dibujen una pajarita. Los resultados mejoran de forma espectacular. Los pego también en el muro y los comparamos (imagen 2).

Proseguimos con media docena más de ejercicios en pósits basados en la idea de que dibujar es fijarse y de cada uno de ellos sacamos alguna conclusión. Sentados en disposición circular alrededor de una gran mesa, se propone que cada persona escriba en un papel sin que nadie más pueda verlo el nombre de un animal, planta o cosa que crea fácil de dibujar y otro que le parezca difícil. Después debe pasar este papel a su compañero de la derecha que deberá dibujar ambas peticiones sin que nadie más las conozca. Los dibujos obtenidos con este ejercicio son examinados por todos nosotros para su desciframiento y en su inmensa mayoría resultan interpretados correctamente. Están, pues, bien dibujados. No hay apenas diferencias de calidad entre aquellas solicitudes que se preveían difíciles y las que se suponían fáciles. Esto es así porque todos poseemos un archivo mental involuntario de cosas 


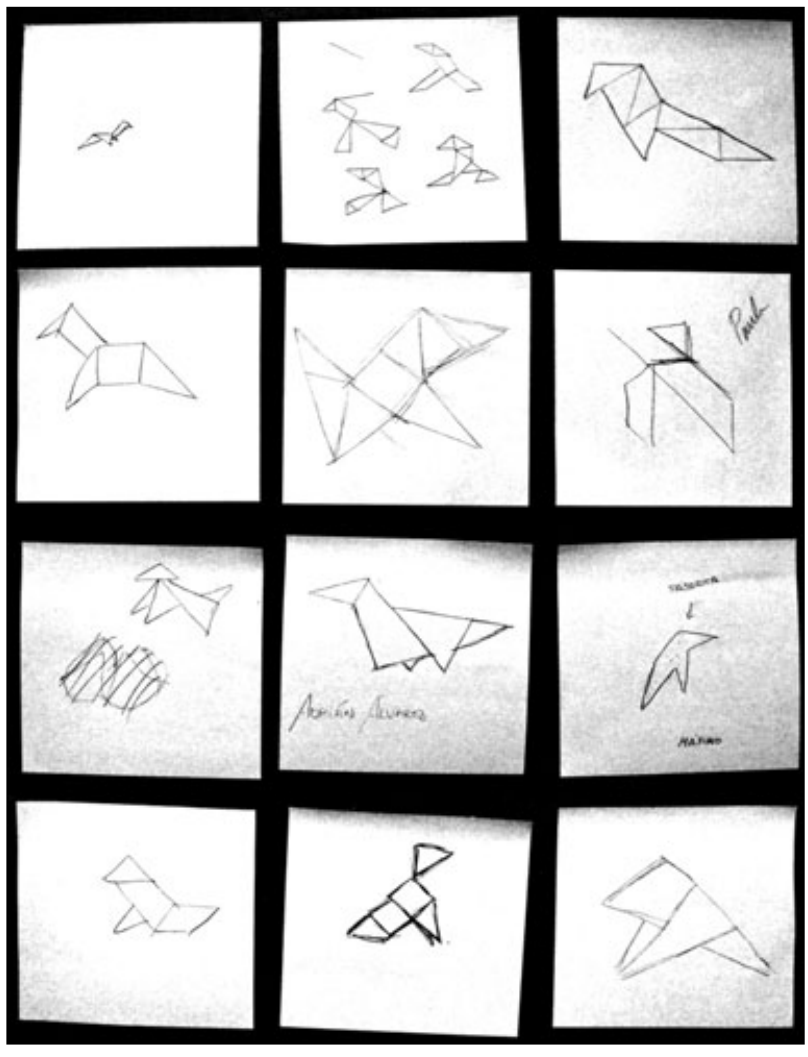

Imagen 1. Pajarita de papel utilizada como modelo.

en las que nos hemos fijado a lo largo de nuestra vida y simplemente tendemos a considerar complicadas de dibujar aquellas que no están todavía incorporadas a esta colección. Un dibujante es una persona que posee un número mucho mayor de piezas en este archivo intangible porque se dedica a ampliarlo con la observación diaria y a conservarlo con la práctica de dibujar.

Los fundamentos de anatomía o perspectiva, las particularidades del trazo de una plumilla o las diferencias entre un dibujo digital de vectores y una imagen de píxeles son conocimientos que pueden adquirirse, por ejemplo, en cursos de ilustración o diseño. Pero para empezar a hacer tebeos nos sirve con saber dibujar y los resultados nos indican que ya sabemos todos dibujar lo suficiente. Podemos hablar ya, entonces, de historietas.

Un bajo eléctrico es un instrumento con un concepto muy sencillo de comprender y formado por muy poquitos

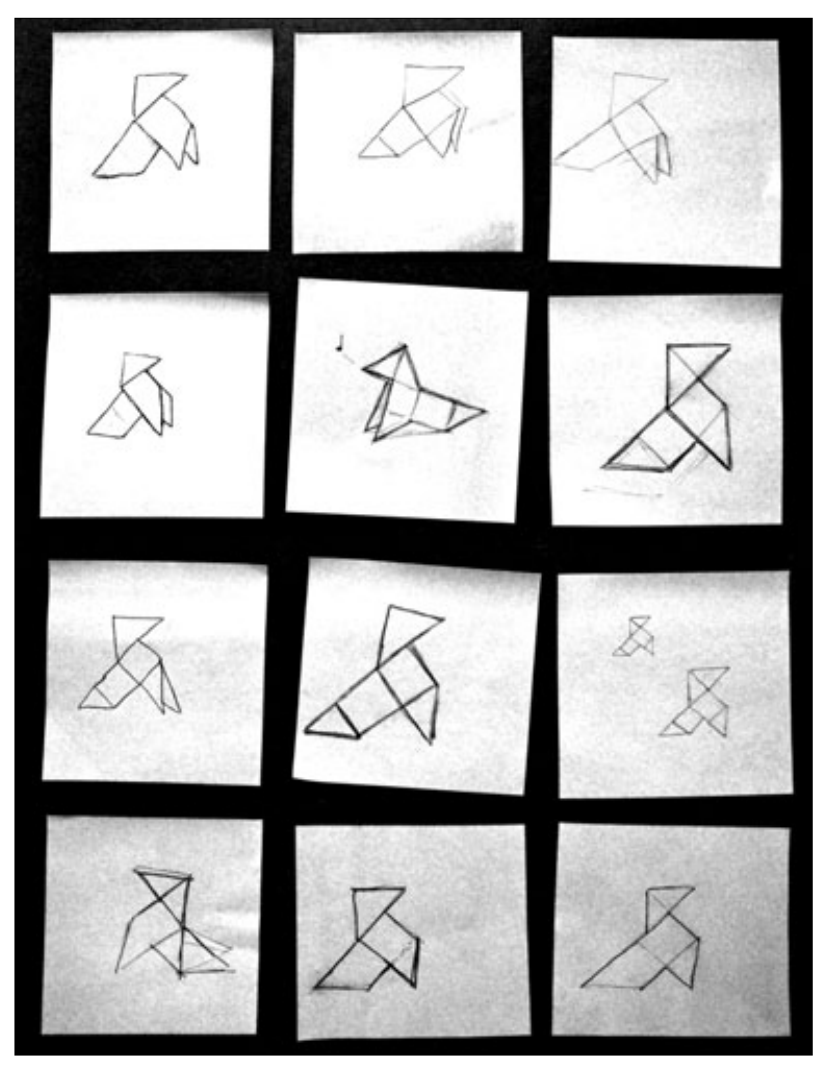

Imagen 2. Pajaritas de papel basadas en la proyección de una fotografía.

elementos básicos. Aprender a tocarlo lo suficiente como para que los oyentes reconozcan el sonido de una melodía es algo muy sencillo. Sin embargo, resulta un instrumento muy difícil de manejar con total maestría y ofrece muchísimas más posibilidades de las que parece en un principio. Algo así pasa con la historieta. Las nociones básicas, pese a que en ocasiones sean el temario completo de cursos historietas que duran meses, se pueden describir en muy poco tiempo. $Y$ eso es lo que intento hacer en poco menos de una hora.

La historieta es un medio de expresión que, en esencia, consiste en contar cosas mediante dibujos y palabras. Mientras los alumnos dibujaban algunos de los ejercicios anteriores he leído sus respuestas a los cuestionarios y he comprobado que muchos de ellos no tienen claros conceptos tan elementales como "viñeta" o "tira", quizás influidos por los medios de comunicación que desde hace unos años tienden a utilizar estos términos erróneamente como sinónimo de 
historieta. Una viñeta es cada uno de los recuadros con dibujos y texto en los que se compone una historieta y suele reflejar los distintos instantes de una historia. Entre cada una de ellas se produce una elipsis o salto temporal. Una tira es una historieta que ocupa solo una fila de viñetas. Los bocadillos son esos espacios en forma de globo limitados por una línea donde se colocan los diálogos que corresponden a cada personaje. Enumero tipos de planos y sus características. Cada uno de ellos tiene sus utilidades. Lo fundamental es saber que, cuanto más amplio sea el plano, mayor porción de espacio recogeremos, pero, cuanto más corto sea y recoja menos espacio, mejor veremos las cosas que estén en él porque nos cabrán más grandes. En Occidente se leen las viñetas de izquierda a derecha y de arriba abajo. Y dentro de cada viñeta los bocadillos de textos también se leen en ese orden. Recalco esto último porque es un error típico de principiantes no respetar este principio. Explico qué son las onomatopeyas y las metáforas visuales, para qué valen las líneas cinéticas y las formas más habituales de representar expresiones. Cuidar las expresiones de nuestros personajes equivale a una buena dirección de actores. Una historieta de un dibujante hábil con la técnica que, sin embargo, ha descuidado las expresiones es una largometraje de gran presupuesto interpretado por actores muy malos. Aconsejo evitar la redundancia entre texto y dibujo, componer visualmente las viñetas dando tanta importancia al texto como al dibujo y, en esta dirección, sugiero rotular el texto íntegro de cualquier viñeta antes de adjudicarle un tamaño preciso para evitar otro error clásico de aficionado: letritas difíciles de ver apelotonadas en globos diminutos. Poca cosa más añado. Ya tenemos todos los elementos para cocinar historietas. Comencemos a hacerlas.

Pido a los asistentes que dibujen ya una página de historieta en un folio a lápiz narrando una historia relacionada con su principal dedicación actual. Por los cuestionarios sé que hay entre ellos la suficiente diversidad de profesiones como para que el resultado no sea monótono. Pueden relatar una anécdota laboral real o inventada, una curiosidad sobre el origen de su empresa, un pensamiento personal... En otras palabras, pueden utilizar el medio para hacer documental, ficción, ensayo, poesía... Insisto en que la historieta es un medio estupendo para contar cualquier cosa. Después les tranquilizo añadiendo que en este momento no deben intentar resultar especialmente ingeniosos. Solo deben contar un hecho, un relato, un pensamiento 0 un sentimiento con dibujos y palabras.
A los que terminan antes, al igual que en ejercicios anteriores, les permito que apliquen un bitono de acuarela a sus trabajos. Según van entregando, pueden irse y doy por terminada la clase. Como tarea, les solicito que piensen en un chiste popular que les haga gracia. Al día siguiente deberán contarlo en clase. Recojo los innumerables pósits con los que hemos ido cubriendo las paredes (imagen 3).

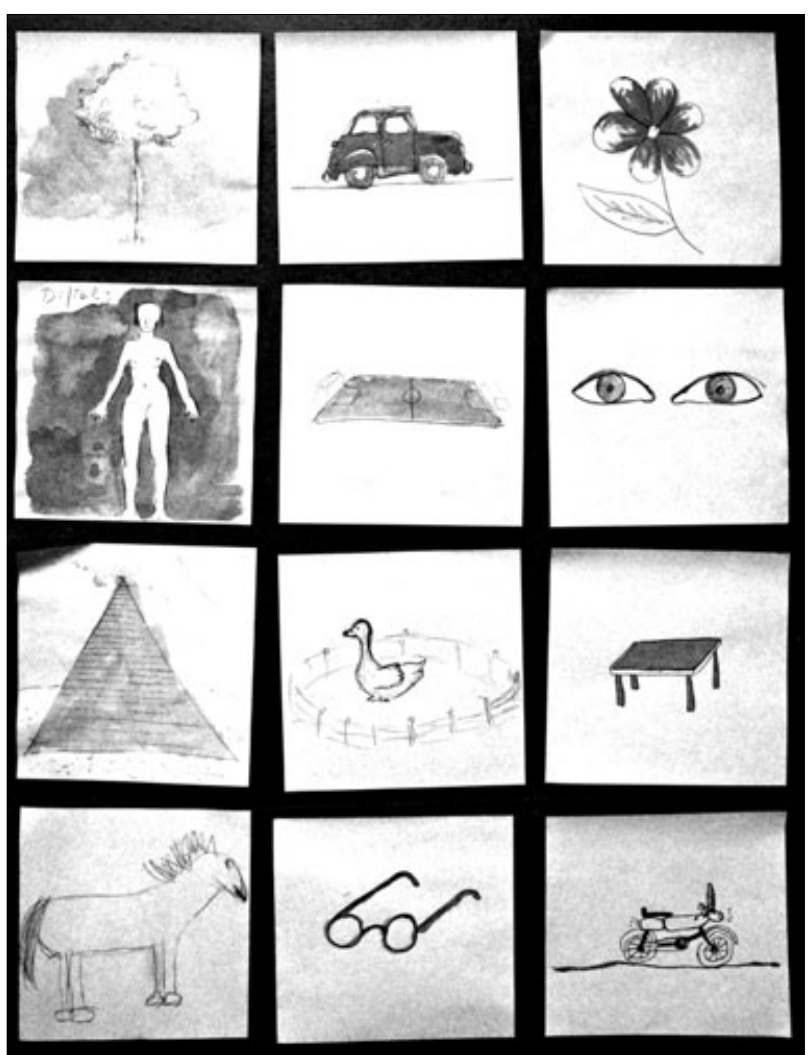

Imagen 3. Pósits con los que se fueron cubriendo las paredes.

\section{DE JUNIO}

La historieta es un medio de expresión creado para ser reproducido y llegar a un gran público. El original es irrelevante. Los colores que no son posibles de reproducir mediante cuatricomía o RGB de pantalla, las líneas demasiado finas, las sutilezas de una textura pictórica no son recursos eficaces a la hora de hacer tebeos. 
He escaneado todos los ejercicios realizados por los alumnos el día anterior y los proyecto a gran tamaño comentándolos. Devuelvo los originales. También he colgado en el blog una selección de los mismos y también los proyecto. Algunos ganan mucho en presencia hasta el extremo de sorprender a sus propios autores, otros empeoran un poquito. Hablamos de la diferencias de tamaños entre originales y reproducción. A mayor original, mayor espacio para añadir detalles con comodidad sobre el papel, pero mayor riesgo de perderlos en la reducción final en papel o pantalla. En una pizarra velleda aboceto cómo se calcula un original proporcional a unas medidas dadas, aclaro qué es la mancha útil, qué es imprimir a sangre.

Proyecto ahora sus historietas y las comento. Es evidente que algunos de los elementos de los que están hechos los cómics, que enumeré ayer con una mínima explicación como las onomatopeyas o las metáforas visuales, se manejan con relativa fluidez. Otros, sin embargo, resultan difíciles de asimilar por la mayoría. Es momento de volver a insistir en conceptos elementales como el orden de los bocadillos en el interior de una viñeta o de concretar las ventajas y desventajas técnicas y expresivas de utilizar distintos tipos de planos.

¿Por qué muchos han dibujado mal las manos a sus personajes 0 , lo que es peor, las han escondido? Nuestras manos están siempre cercanas por si necesitamos fijarnos en ellas, no seamos ruines y no las escaqueemos en nuestros dibujos. En registros no realistas podemos, eso sí, por razones de expresividad, dibujarlas con menos dedos. Propongo ejercicios y juegos de pósits sobre este asunto que van a parar de nuevo a las paredes para ser comentados (imagen 4).

Tras una pausa en una de las terrazas privadas del precioso edificio en el que nos encontramos confío a uno de los alumnos un rotulador de punta gruesa y pósits de distintos colores para que me asista en la pequeña charla en la que intentaré resumir mi teoría personal sobre la arquitectura del humor.

La tesis básica que mantengo es que el discurso humorístico se fundamenta en la transmisión de cualquier mensaje de forma directa obviando porciones de información que, aun siendo en principio imprescindibles para la comprensión de aquel, el receptor ya conoce por otras fuentes. El humor emplea este atajo para transmitir un mensaje complejo en un flash lúcido. La "gracia" no es otra cosa que la sensación satisfactoria que otorga la resolución inconsciente del mensaje cifrado recibido. Esto supone, por tanto, que para que

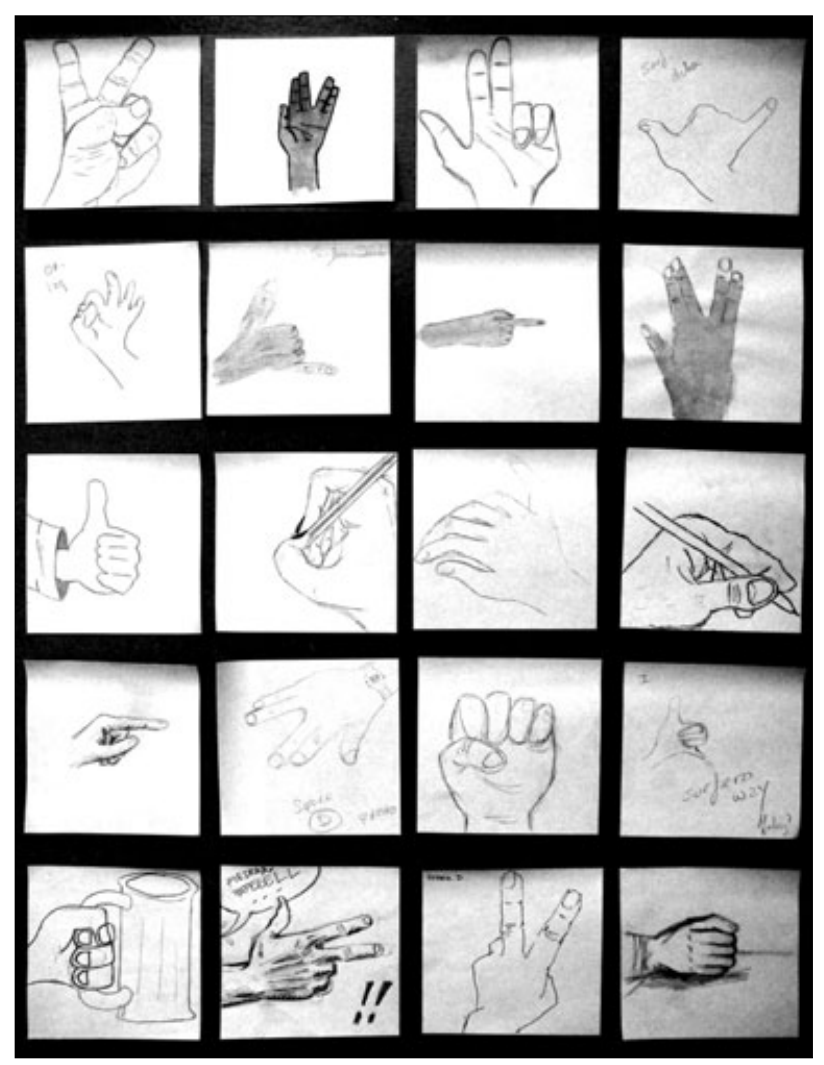

Imagen 4. Ejercicios y juegos de pósits plasmados también en la pared.

un chiste haga gracia el receptor debe tener determinada información previa común con el emisor para ser capaz de juntar todas las piezas del mensaje. No podemos contar un chiste a un extraterrestre. También indica que un chiste es tanto más gracioso cuanto menos gente lo entiende. Un chiste comprendido por todo el mundo porque en su transmisión no se ha producido este proceso de escatimar información esencial, no es un chiste; es un comentario. El humor es, en definitiva, una forma de comunicar. Una de las más eficientes. No existen anécdotas graciosas y otras que no lo son. Cualquier relato, pensamiento, sentimiento o simple descripción puede transmitirse humorísticamente.

Estimo que existen alrededor de media docena de mecanismos comunicativos comunes a todas las culturas y épocas que, cuando se utilizan del modo descrito, producen un formato específico que es conocido bajo el nombre de chiste. Sin alguno 0 varios de estos mecanismos, la intención humorística se percibe como tal pero no como un verdadero chiste. 
Según voy enumerando los mecanismos más comunes pido a mi asistente que escriba sus nombres con su rotulador en pósit de color verde que voy pegando en un muro de la clase definiendo sus características e ilustrándolos oralmente con ejemplos de chistes populares concretos que los utilizan. Son la hipérbole, el juego de palabras, el equívoco, la ironía y la ironía inversa, la contradicción, la desviación de discurso y el razonamiento perverso. En pósits de color amarillo indico las manifestaciones particulares de alguno de ellos (imagen 5). La analogía, la metáfora y la alegoría son tipos de comparaciones, por ejemplo; mientras que el retruécano y otros tropos los consideramos clases de juegos de palabras.

La mayoría de los ejemplos enunciados no han producido un espectacular efecto hilarante en la clase, pero sí que se han percibido como chistes. Son, de hecho, lo que popularmente se conoce como "chistes malos". Discursos humorísticos que utilizan mecanismos pero carentes de condimentos. Denomino condimentos a aquellos añadidos temáticos que intensifican la percepción humorística de cualquier chiste. Los condimentos se clasifican en tres grandes grupos comunes a muchas culturas. Son los tabúes, la ruptura de protocolo y la identificación. Pero las formulaciones específicas de estos tres condimentos, que añadimos con otro color más de pósits, no son siempre comunes a todas las culturas y épocas. En nuestra realidad sociocultural los tabúes son, en esencia: sexo, religión, drogas y escatología. La identificación se obtiene, por ejemplo, con referencias a la actualidad y con alusiones que refuercen la pertenencia a un grupo. La ruptura de protocolos puede ser de naturaleza social, de contraste de registros 0 por metalenguaje, anacronismos 0 surrealismo.

Empiezo a contar chistes populares que, esta vez, a juzgar por las risas, sí que son percibidos como graciosos. Tras cada uno de ellos señalo los mecanismos que utiliza y los condimentos que contiene.

Recalco: un mecanismo sin condimento es un chiste malo, pero cualquier acumulación de condimentos no será verdadero chiste si no echa mano de, al menos, un mecanismo. Advierto: la mayoría de los humoristas lo hacen inconscientemente, de la misma forma que un guitarrista que improvisa no piensa en escalas y armonías conscientemente. Sin embargo, en ambos casos el correcto funcionamiento depende de la adecuada compensación de esa estructura.

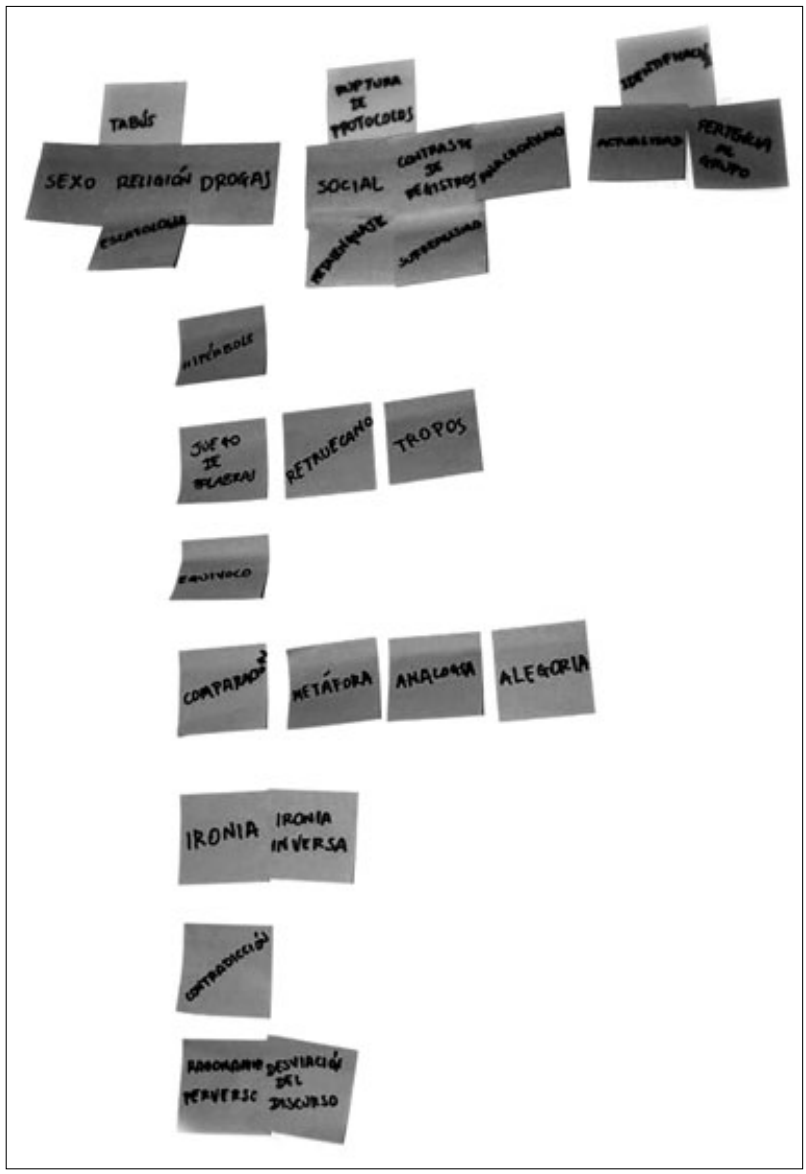

Imagen 5. Muestra de algunos mecanismos comunicativos comunes a todas las culturas.

Solicito que vayan contando en voz alta los chistes que pedí ayer que pensaran. Voy desmigando qué mecanismos y condimentos utiliza cada uno y el efecto que producen. Como ejercicio, pido que narren en un tebeo con una 0 varias viñetas otro chiste popular distinto al que acaban de contar. Cuando entregan, doy por terminada la clase.

\section{DE JUNIO}

Proyectamos los chistes populares en formato de historieta que dibujados ayer. Afirmo que, para mí, el humor gráfico de prensa no es otra cosa que una especialidad de la historieta cuya unidad narrativa acostumbra a desarrollarse en una única viñeta. Su denominación procede más de la necesidad 
de algunos de sus creadores de distanciarse de un medio de expresión poco valorado cultural y económicamente que de una especificidad real. Todo es contar con dibujos y palabras. No comparto la definición de Scott McCloud que asegura que debe existir secuencia para que una narración gráfica pueda llamarse cómic. En los trabajos de los alumnos proyectados volvemos a toparnos con un puñado de conflictos de uso de los elementos que componen un cómic y que entorpecen la comprensión de lo que se quería contar, pero ya no son tan abundantes como en los ejercicios del primer día. En la mayoría de los casos, basta indicar el error para que el autor plantee por sí mismo una posible forma de solucionarlo. También deducimos, entre todos los miembros de la clase, los mecanismos y condimentos con los que esos chistes populares están construidos.

Tras el descanso, me propongo relatar la historia mundial del cómic en solo una hora. Para ello voy a armar otro gran esquema a base de pósits de colores adheridos a una de las paredes de clase (imagen 6), pero también necesito un ayudante que se haga cargo del ordenador y proyecte, tras localizarlos en Google, ejemplos de páginas e ilustraciones de todo autor que yo mencione, de modo que ilustre en tiempo real mis palabras. También he traído dos docenas de tebeos de mi colección para ir enseñándolos según toque. Los cuestionarios del primer día me han alertado de que muchos de los presentes desconocen el verdadero significado de los formatos editoriales más populares y quiero que observen, toquen, hojeen y aprecien las diferencias entre un comic-book de superhéroes americano, un álbum franco-belga de tapa dura, una novela gráfica contemporánea, un "prestige", un ejemplar del $T B O$ original de principios de siglo, un cuaderno apaisado de historietas español de tiempos de la dictadura franquista, una revista de cómics para adultos de los años ochenta, etc.

Mi relato es cronológico, desarrolla en paralelo lo sucedido en Estados Unidos, Europa y Japón y no se centra en autores 0 tendencias. Se apoya más bien en las particularidades sociales, culturales, políticas y económicas de la historia del siglo XX que originaron puntos de inflexión en la de los cómics dando lugar a su vez a formas de divulgación del medio específicas, escuelas estilísticas particulares y autores destacados. Aunque obvio los centros de producción menos relevantes incorporo también lo sucedido en nuestro país por motivos de cercanía

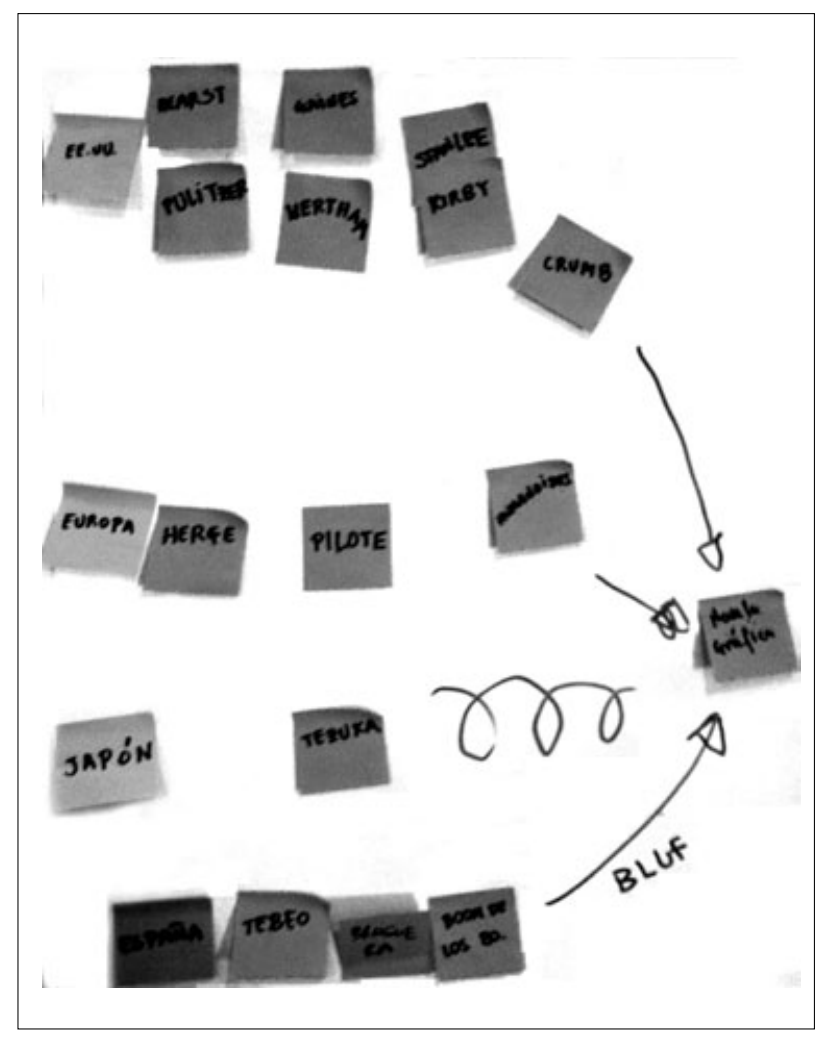

Imagen 6. Gran esquema a base de pósits sobre la historia mundial del cómic.

sentimental. Hablo del enfrentamiento de Hearst y Pulitzer, de la época dorada de los cómics de prensa y de los syndicates, del TBO, de la gran depresión, de Hergé, de la guerra civil española, de la Segunda Guerra M undial, de Tezuka, de la caza de brujas, de Wertham, de la EC de Gaines, del comics code, de la revista Pilote, de Stan Lee y la edad de plata de los superhéroes, del 68, de la contracultura y el comix underground, de los Humanoides Asociados, de la transición española, del falso boom del cómic y de la novela gráfica.

Volvemos a la práctica. Ahora se trata de realizar entre toda la clase, a razón de una viñeta por alumno, una gran historieta. El mundial de fútbol que se está celebrando en Sudáfrica es una realidad común a todos que nos servirá de nexo. Cada uno deberá dibujar una razón por la que le gusta 0 no ese deporte e ilustrarla con un comentario o chiste gráfico humorístico en un pósit que recojo al finalizar la clase. 


\section{DE JULIO}

He agrupado todas las viñetas del último ejercicio de ayer en una sola plancha. Sostengo que un chiste popular o gráfico requiere siempre de la utilización de, al menos, un mecanismo. Sin embargo, un discurso humorístico de cierta extensión como un monólogo o una historieta larga son formatos que no necesitan que cada uno de sus fragmentos utilice un mecanismo; es decir, que sea un chiste. Al contrario, la correcta alternancia de comentarios humorísticos -aquellos que contienen condimentos pero no mecanismos-con chistes contribuye a crear el ritmo que añade impacto a estos últimos. Al proyectar todos los pósits componiendo una única historieta que alterna por azar comentarios humorísticos y chistes sobre un tema común, el resultado es que unos y otros funcionan mejor que si se presentasen por separado.

Por otra parte, sigo actualizando el blog a diario con trabajos de los alumnos y han comenzado a aparecer ya algunos comentarios de los lectores.

La charla de hoy aborda los aspectos económicos y laborales de la profesión en nuestro país y época. Es bueno saber que en nuestro sector espacio-temporal el 99 por ciento de los que se ganan de verdad la vida con este trabajo pertenecen a uno de estos tres tipos: los que lo compaginan con otras actividades, los que trabajan para el extranjero y los que hacemos humor. Un autor que no pertenezca a uno de estas categorías y encuentre tiempo para dibujar los cientos de páginas que exige la realización de una novela gráfica es porque vive de sus padres 0 de su pareja.

Podemos vender nuestro trabajo a publicaciones periódicas como revistas y diarios en los que nos pagarán una cantidad fija a cambio de los derechos de publicación para una sola vez y se reservarán con ello un tiempo de exclusividad de ese encargo en concreto. En ninguna de ellas nos ofrecerán un contrato laboral con seguridad social, sueldo y vacaciones pagadas. Deberemos ser autónomos. También podemos vender nuestro trabajo inédito o publicado con anterioridad en publicaciones periódicas para su edición en formato libro. En ese caso solo percibiremos un porcentaje de lo obtenido con las ventas. Nosotros no vendemos originales como los pintores, vendemos derechos de reproducción. Pormenorizo las cláusulas en las que conviene fijarse a la hora de firmar un contrato editorial. Analizo la idea clave de "adelanto de derechos", un concepto cuyo nombre induce a equívoco. Trazo en la pizarra un gráfico que desgrana cómo se reparte el precio de venta al público de cualquier libro, incluidos los de historietas, entre los eslabones de la cadena que hace que llegue hasta el lector (imagen 7). Aproximadamente, la librería y la distribuidora se quedan el 50 por ciento, la editorial obtiene un 40 por ciento y el autor, en el mejor de los casos, percibirá un 10 por ciento. Detallo pormenores que en ocasiones modifican estos porcentajes. También me extiendo sobre los gastos, riesgos y beneficios de cada uno de los eslabones. Explico el sistema de devoluciones que existe en Europa, lo comparo con el norteamericano de venta directa y razono las ventajas y desventajas de cada sistema.

Hoy quiero que comiencen a trabajar, por fin, en una historieta de cierta entidad (mínimo dos folios) con un guión y un pequeño story previo que deberé aprobar antes de su realización. Me interesa que todos traten un tema cotidiano y común a todos para que, procurando no coincidir con el compañero, se fuercen a resultar originales buscando un enfoque no demasiado tópico. Elijo la huelga de metro con la que estamos conviviendo esta misma semana en Madrid.

Paseo entre ellos resolviendo dudas de manera personal 0 en pequeños grupos. Acaba la clase.

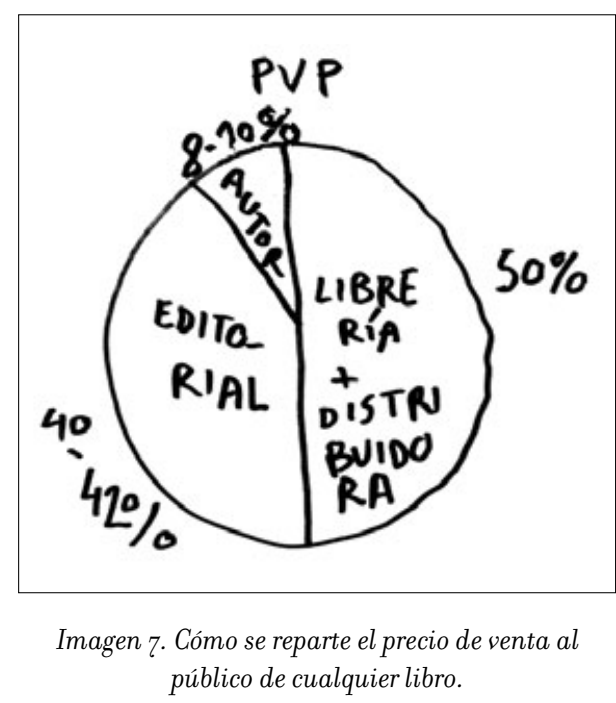

doi: 10.3989/arbor.2011.2extran2124 
2 DE JULIO

No empezamos con la proyección habitual porque no hay nuevos trabajos terminados. En su lugar, adjudico tiempo para que sigan dibujando las historietas que no pudieron acabar ayer. Voy comprobando cómo ejecutan en limpio los storys propuestos. Nunca critico las soluciones narrativas que no me atraen como lector. Cualquier proceso creativo es, sobre todo, decidir; y las decisiones, si reman a favor de la intención, son siempre respetables. Intervengo, tan solo, cuando la determinación tomada va en contra de la legibilidad de lo que se pretende relatar. Considero que las habilidades técnicas más específicas pueden aprenderse con posterioridad, pero deseo que todos los participantes en el curso terminen sabiendo comunicar lo que deseen en formato tebeo.

Para la última charla he traído una selección de trabajos personales que proyecto en la gran pantalla. Ya que ellos llevan días enseñándome su trabajo, decido enseñarles el mío. Una imagen me sirve para aclarar alguna particularidad técnica, en la siguiente relato una anécdota laboral relacionada que ilustra aspectos ruines del mundillo, otra me da pie para establecer el paralelismo existente entre los fanzines analógicos de hace años y los webcomic actuales. También hablo de estrategias para buscar espacios donde publicar, concursos, ferias, redacciones, currículos, impagos, sistemas de reproducción mecánica, condicionantes económicos a la creación y de trabajar en pijama. Nuestra profesión es inestabilidad y soledad, sí; pero también libertad.

Estoy contento con la calidad media de las historietas realizadas. Sin embargo, como hoy es el último día del taller no podré llevarme los originales para escanear y devolverlos mañana. No hay problema: un alumno fotografía a gran resolución todas las obras y me las entrega en una llave USB. Mañana las subiré todas al blog.

Tras las despedidas, entrego como regalo a cada asistente uno de mis últimos libros publicados.

Recibido: 24 de septiembre de 2010

Aceptado: 10 de diciembre de 2010 